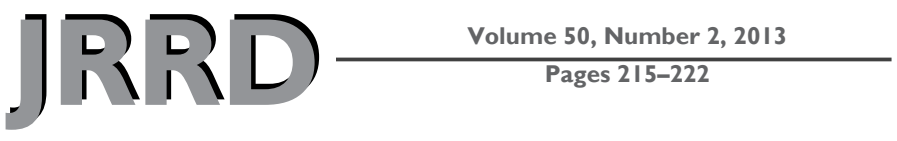

\title{
Bilateral differences in lower-limb performance in individuals with multiple sclerosis
}

\author{
Rebecca D. Larson, PhD; ${ }^{*}$ Kevin K. McCully, PhD; Daniel J. Larson, PhD; William M. Pryor, MS; Lesley J. \\ White, PhD \\ Department of Kinesiology, University of Georgia, Athens, GA
}

\begin{abstract}
Bilateral differences in lower-limb strength in people with multiple sclerosis (MS) have been clinically observed. The objectives of this study were to quantify bilateral differences in lower-limb performance and metabolism during exercise. Eight ambulatory individuals with mild MS with an Expanded Disability Status Scale score of $2.6+/-1.6$ and seven non-MS controls completed bilateral assessments of muscle strength and incremental cycling. Individuals with MS had significant $(p<0.05)$ between-leg differences in leg strength (strong leg: 43.3 +/- $12.7 \mathrm{~kg}$ vs weak leg: $37.7+/-$ $15.2 \mathrm{~kg}$ ), peak oxygen uptake (strong leg: $13.7+/-3.2 \mathrm{~mL} / \mathrm{kg} /$ min vs weak leg: $10.6+/-3.0 \mathrm{~mL} / \mathrm{kg} / \mathrm{min})$, and peak workload (strong leg: $73.4+/-22.3 \mathrm{~W}$ vs weak leg: $56.3+/-26.2 \mathrm{~W}$ ). No between-leg differences were found in controls ( $p>0.05)$. As anticipated, individuals with MS exhibited significantly greater asymmetry for strength, oxygen uptake, and workload than controls $(p<0.05)$. The differences between legs varied from $2 \%$ to $30 \%$ for maximal strength and $4 \%$ to $66 \%$ for cycling workload in the MS group and $4 \%$ to $24 \%$ and $0 \%$ to $8 \%$ for the control group, respectively. Preliminary evidence suggests that the magnitude of differences may be related to limitations in aerobic function.
\end{abstract}

Key words: ambulatory, asymmetry, bilateral, cycling, leg performance, lower limb, multiple sclerosis, muscle, oxygen uptake, strength.

\section{INTRODUCTION}

Multiple sclerosis (MS) is a chronic and progressive autoimmune disease of the central nervous system [1]. Symptoms vary widely across individuals; however, fatigue is a common complaint [2-5], with 40 percent of those surveyed identifying it as their most disabling symptom [2,4]. Fatigue has been defined as, "a subjective lack of physical or mental energy that is perceived by the individual or caregiver to interfere with activities of daily living" [5]. This type of fatigue is often referred to as symptomatic fatigue to distinguish it from muscular fatigue.

Muscular fatigue in individuals with MS is often described as being related to central and/or peripheral impairments. Central impairment presents itself as declines in efferent motor outflow (neural drive) to the muscle resulting in activation failure, reduced muscle recruitment [6], and/or delayed neural transmission [7], while peripheral impairment reflects reduced forcegenerating mechanisms [8] within the skeletal muscle as a result of altered metabolic characteristics [9-11]. The relationship between symptomatic and muscular fatigue is complicated because of their interrelated influences.

\footnotetext{
Abbreviations: $6 \mathrm{MWT}=6$-minute walk test, $\mathrm{CI}=$ confidence interval, EDSS = Expanded Disability Status Scale, EMG = electromyography, HR = heart rate, MFIS = Modified Fatigue Impact Scale, MS = multiple sclerosis, MVIC = maximal voluntary isometric contraction, POMS-B = Profile of Moods State-Brief Version, $\mathrm{RPE}=$ rating of perceived exertion, $\mathrm{SD}=$ standard deviation, $\mathrm{VO}_{2}=$ oxygen uptake.

*Address all correspondence to Rebecca D. Larson, PhD; Department of Health and Exercise Science, University of Oklahoma, Norman, OK 73019. Email: rdlarson@ou.edu http://dx.doi.org/10.1682/2011.10.0189
} 
Clinical examinations of individuals with MS have often observed differences in strength and function between legs [12]. The differences in leg strength have also been reported in the scientific literature [13]. In a 2005 case study, White and Dressendorfer reported bilateral differences in leg performance in an individual with exertional monoparesis [14]. Additionally, leg power asymmetry, unilateral leg weakness, and differences in bone density have been observed in people with MS [13,15-17]. Despite these observations, less is known about aerobic metabolism and endurance performance during dynamic lower-limb activity.

Therefore, the first purpose of this study was to formally quantify whether ambulatory individuals with mild MS would display bilateral differences in lower-limb performance and metabolism during exercise. We hypothesized that ambulatory individuals with mild MS would exhibit between-leg differences in strength, peak oxygen uptake $\left(\mathrm{VO}_{2}\right)$, and maximal cycling workload during incremental exercise and that these differences would be greater than those seen in nondisabled controls. Second, we explored the relationship between bilateral differences and a functional performance test, the 6-minute walk test (6MWT).

\section{METHODS}

\section{Participants}

Fifteen volunteers, eight with MS (6 female and 2 male) and seven nondisabled controls (5 female and 2 male) participated in the study. We included individuals with MS if they had a physician diagnosis of relapsingremitting MS [18], had an Expanded Disability Status Scale (EDSS) score of $<6.5$ (ambulatory without aid), and had not experienced an exacerbation for a minimum of 6 mo prior to enrollment. We excluded participants with multiple risk factors for cardiovascular disease (according to American College of Sports Medicine guidelines) or orthopedic limitations, regardless of MS status [19]. Each participant had physician's clearance and signed a consent form approved by the University of Georgia Institutional Review Board prior to participation.

\section{Study Design}

Each participant underwent assessments of leg extensor strength and limb-specific $\mathrm{VO}_{2}$. Prior to formal assessments, participants were familiarized with and practiced all testing procedures. To maximize consistency, we tested participants at approximately the same time of day and asked them to abstain from exercise, alcohol, caffeine, and smoking for $12 \mathrm{~h}$ prior to the visit. We separated testing sessions by a minimum of $48 \mathrm{~h}$ to ensure adequate recovery. Additionally, since the legs were tested on different days, we used questionnaires related to fatigue (Modified Fatigue Impact Scale [MFIS] physical domain) and the Profile of Moods State-Brief Version (POMS-B) for daily screening purposes. If a participant's score on either the MFIS physical domain or the POMS-B were 2.5 standard deviations (SDs) higher than their previous scores, we retested them at a later date once fatigue levels returned to normal levels. We measured self-reported physical activity using a questionnaire developed in-house that asked about frequency, duration, and intensity of physical activity during a typical week. We measured whole-body and limb-specific lean and fat mass by dual-energy X-ray absorptiometry (Lunar iDXA, GE Healthcare; Chalfont St. Giles, Bucks, United Kingdom) to verify that legs were similar between and within groups.

\section{Muscle Strength}

We assessed quadriceps strength of each leg by maximal voluntary isometric contractions (MVICs) using a custom chair that set the knee angle at a constant $70^{\circ}$. We stabilized the participant's thigh and torso during testing. We connected the lever arm of the chair to a force transducer, and the digitized signal was sent directly to a computer and recorded using MATLAB (MathWorks; Natick, Massachusetts). Following a brief warm-up consisting of three submaximal contractions and a 5 min rest period, the participant performed three MVICs using the highest value to determine the strong leg (less affected) and the weak leg (more affected).

\section{Unilateral Incremental Cycling}

We assessed limb-specific peak $\mathrm{VO}_{2}$ (one-legged cycling) using a continuous ramp protocol. Prior to testing, the participant completed a standardized 2 to $3 \mathrm{~min}$ warm-up of cycling at $25 \mathrm{~W}$, followed by a 5 min rest period. After the warm-up, single-leg cycling started at $0 \mathrm{~W}$ and increased $1 \mathrm{~W}$ every $2 \mathrm{~s}$ until he or she met one of our defined test termination criteria: (1) any symptomimpairing ability to continue or indication of risk to participant's safety or health, (2) volitional exhaustion, or (3) pedaling rate below $40 \mathrm{rpm}$ (rotations per minute). 
We used these criteria for all subsequent tests. We measured expired gases continuously using a calibrated metabolic cart (TrueMax 2400, ParvoMedics; Sandy, Utah) and averaged them over $30 \mathrm{~s}$ intervals. We recorded heart rate (HR) by telemetry (RS800, Polar Electro; Kempele, Finland) and obtained overall ratings of perceived exertion (RPEs) using a Borg 10-point scale at the end of each minute [20]. We measured blood lactate by finger stick performed at rest before and 3 min after the exercise test (Lactate Pro; Carlton, New South Wales, Australia). The interclass correlation for repeated measures for peak $\mathrm{VO}_{2}$ was 0.96 (confidence interval [CI]: 0.84-0.99) and for peak workload was 0.96 (CI: 0.89-0.99).

\section{Single-Leg Cycling Leg Position}

During all single-leg cycling tests, we securely fastened the participant's foot to the pedal and positioned the nonexercising leg to ensure no contribution to workload. We positioned the exercising leg so that it was almost fully extended when the crankarm was at the lowest position.

\section{Functional Performance Test: 6-Minute Walk Test}

We used the 6MWT as a measure of exercise tolerance and overall functional limitation [21]. We conducted this test according to McGavin et al. [22]. It has previously been used in studies with individuals with MS.

\section{Statistical Analysis}

We performed all analyses using SPSS version 16 (IBM Corporation; Armonk, New York). We used independent $t$-tests to detect across-group differences and dependent $t$-tests to compare across-limb differences. We used a correlation to assess the relationship among leg differences and performance during the 6MWT. Data are expressed as mean $\pm \mathrm{SD}$. An alpha of 0.05 was our criteria to establish statistically significant differences. We reported precise $p$-values, and when appropriate, Cohen's $d$. Based on White and Dressendorfer [14], we determined that changes $\geq 25$ percent could be detected in leg differences using strength, peak workload, and peak $\mathrm{VO}_{2}$, corresponding to an effect size of $\sim 0.8$ and power of approximately 80 percent. Using this information, we calculated our sample size to be approximately 7 to 10 participants per group.

\section{RESULTS}

\section{Participant Characteristics}

Eight ambulatory (no assistance devices) individuals with relapsing-remitting MS, in remission, and seven nondisabled controls completed the study. The EDSS score of $2.6 \pm 1.6$ indicated a mild to moderate impairment in the participants with MS. Duration of the disease was $12.6 \pm 8.1 \mathrm{yr}$ (ranging from 6-31 yr). Age, height, weight, body mass index, percent body fat, and self-report of physical activity were not statistically different between groups (Table 1). Leg lean and fat mass were not statistically different between legs or groups $(p>0.05)$.

\section{Leg Strength}

MVIC was statistically different between legs in the group with MS (strong leg: $43.3 \pm 12.7 \mathrm{~kg}$, weak leg: $37.7 \pm 15.2 \mathrm{~kg}, p=0.004$, effect size: Cohen $d=1.20$ [which is considered large [23]]), whereas the control group did not exhibit statistical differences between legs (strong leg: $39.8 \pm 12.1 \mathrm{~kg}$, weak leg: $37.9 \pm 15.2 \mathrm{~kg}, p=$ 0.40 ). The average difference in isometric strength was $18.2 \pm 9.4$ percent (range: $2 \%-30 \%$ ) in the group with MS and $11.3 \pm 7.9$ percent (range: $4 \%-24 \%$ ) in the control group. As expected, the difference between legs was significantly greater in the group with MS than in controls (MS: $8.34 \pm 5.7 \mathrm{~kg}$, control: $2.1 \pm 6.1 \mathrm{~kg}, p<0.01$, effect size: Cohen $d=1.1$ [which is considered large [23]]) (Figure 1).

\section{Unilateral Incremental Exercise}

Table 2 summarizes the unilateral incremental exercise test results for both groups. Peak $\mathrm{VO}_{2}$ (milliliters per kilogram per minute) and peak workload (watts) were statistically different between legs for the individuals with

Table 1.

Participant characteristics.

\begin{tabular}{lccc}
\hline \multicolumn{1}{c}{ Characteristic } & $\begin{array}{c}\text { MS } \\
(\boldsymbol{n}=\mathbf{8})\end{array}$ & $\begin{array}{c}\text { Control } \\
(\boldsymbol{n}=7)\end{array}$ & $\begin{array}{c}\boldsymbol{p} \text { - } \\
\text { Value }\end{array}$ \\
\hline Age (yr) & $51.6 \pm 9.2$ & $49.4 \pm 14.3$ & 0.74 \\
Height (cm) & $167.5 \pm 7.5$ & $169.1 \pm 9.0$ & 0.72 \\
Body Mass (kg) & $70.4 \pm 13.8$ & $75.4 \pm 30.4$ & 0.74 \\
Body Mass Index $\left(\mathrm{kg} / \mathrm{m}^{2}\right)$ & $25.0 \pm 3.9$ & $26.0 \pm 8.3$ & 0.77 \\
Fat Mass (\%) & $39.4 \pm 6.1$ & $36.9 \pm 8.7$ & 0.52 \\
Frequency of Exercise (d/wk) & $2.8 \pm 2.5$ & $3.8 \pm 1.9$ & 0.58 \\
Duration of Exercise Sessions (min) & $30.0 \pm 11.3$ & $42.9 \pm 25.1$ & 0.25 \\
\hline MS = multiple sclerosis. & & & \\
\hline \hline
\end{tabular}




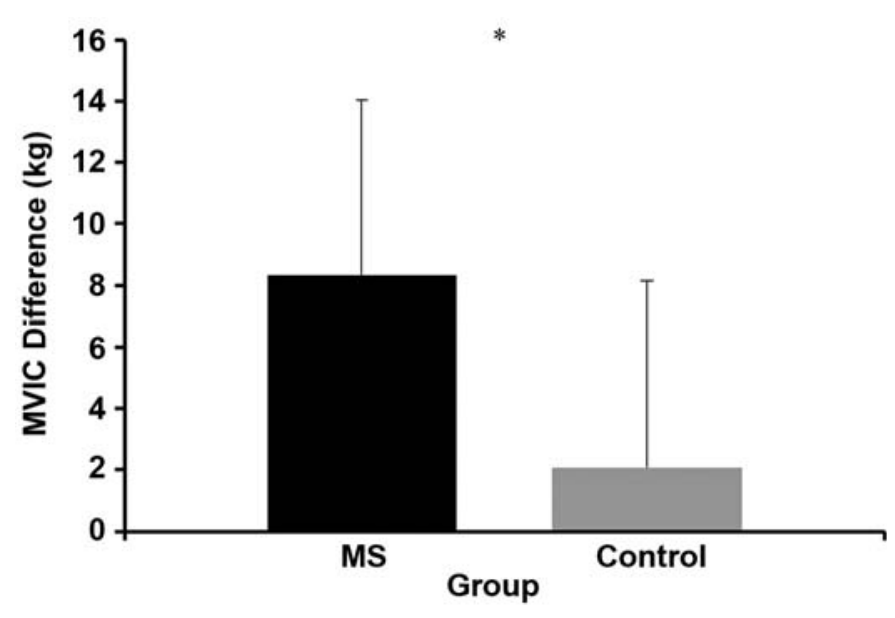

Figure 1.

Difference in maximal isometric strength of quadriceps (strong weak). Values are mean \pm standard deviation. ${ }^{*} p<0.05$ represents statistically significant differences in group means. MS = multiple sclerosis, MVIC = maximal voluntary isometric contraction.

MS $(p<0.05)$ (peak $\mathrm{VO}_{2}$ : Cohen $d=1.8 \mathrm{~mL} / \mathrm{kg} / \mathrm{min}$, workload: Cohen $d=1.2 \mathrm{~W}$ ) with no statistical differences observed between legs for respiratory exchange rate, peak lactate, peak HR, ventilation, and RPE. We observed no statistical differences between legs in the control group for all the measured variables. The average difference between legs for maximal work was $28.0 \pm$ 21.3 percent (range: $4 \%-66 \%$ ) and $4.3 \pm 2.8$ percent (range: $0 \%-8 \%$ ) for the individuals with MS and controls, respectively. As anticipated, bilateral leg differences were significantly greater in the group with $\mathrm{MS}$ for peak $\mathrm{VO}_{2}$ and peak workload than in controls (MS: $3.1 \pm 1.9 \mathrm{~mL} / \mathrm{kg} /$ min, control: $0.83 \pm 2.0 \mathrm{~mL} / \mathrm{kg} / \mathrm{min}, p<0.05$, Cohen $d=$
1.2; MS: $18.1 \pm 14.0 \mathrm{~W}$, control: $-0.57 \pm 5.1 \mathrm{~W}, p<0.01$; Cohen $d=1.7$, respectively [which are both considered large [23]]) (Figures 2-3).

\section{Six-Minute Walk Test}

The individuals with MS covered significantly less distance during the 6MWT than controls (MS: $474.3 \pm$ $93.1 \mathrm{~m}$, control: $626.9 \pm 94.0 \mathrm{~m}, p<0.05)$. We also observed a between-group significant correlation between the 6MWT and leg differences in peak workload $(r=-0.65, p<0.05)$.

\section{DISCUSSION}

The major findings of this study indicate that ambulatory individuals with relapsing-remitting MS and relatively low disability exhibited statistically significant bilateral differences in leg strength, oxidative capacity (peak $\mathrm{VO}_{2}$ ), and work performed and that these differences were significantly greater than controls. Additionally, people with MS displayed a larger range of bilateral differences than controls, especially when measured during cycling rather than maximal isometric strength. Preliminary evidence suggests that the magnitude of bilateral differences might limit functional abilities. These findings suggest that, despite being ambulatory and having low disability, our sample of people with MS not only exhibited significant performance differences between limbs but that these differences were significantly greater than the differences observed in our control group.

People with MS often experience decrements in motor drive, which often affects the lower limbs disproportionally [12]. Despite this knowledge, many published reports

Table 2.

Metabolic and associated measures during single-leg incremental cycling test. Values are mean \pm standard deviation.

\begin{tabular}{|c|c|c|c|c|c|c|}
\hline \multirow{2}{*}{ Variable } & \multicolumn{3}{|c|}{ MS } & \multicolumn{3}{|c|}{ Control } \\
\hline & Stronger Leg & Weaker Leg & $p$-Value & Stronger Leg & Weaker Leg & p-Value \\
\hline Peak $\mathrm{VO}_{2}(\mathrm{~mL} / \mathrm{kg} / \mathrm{min})$ & $13.7 \pm 3.2$ & $10.6 \pm 3.0$ & $0.002^{*}$ & $18.1 \pm 5.8$ & $17.2 \pm 5.3$ & 0.31 \\
\hline Peak Workload (W) & $73.4 \pm 22.3$ & $56.3 \pm 26.2$ & $0.01^{*}$ & $98.7 \pm 26.7$ & $99.3 \pm 27.1$ & 0.78 \\
\hline Lactate (mmol/L) & $5.1 \pm 2.6$ & $4.2 \pm 1.9$ & 0.26 & $4.67 \pm 1.2$ & $4.6 \pm 1.5$ & 0.92 \\
\hline Maximal HR (beats/min) & $130.9 \pm 19.2$ & $121.8 \pm 22.3$ & 0.09 & $138.7 \pm 17$ & $141.1 \pm 19.1$ & 0.25 \\
\hline Pain & $2.5 \pm 2.9$ & $1.1 \pm 2.1$ & 0.15 & $3.0 \pm 3.0$ & $2.9 \pm 3.0$ & $>0.99$ \\
\hline
\end{tabular}

${ }^{*} p<0.05$ represents statistically significant differences in group means.

$\underline{\mathrm{HR}}=$ heart rate, $\mathrm{MS}=$ multiple sclerosis, $\mathrm{RER}=$ respiratory exchange ratio, $\mathrm{RPE}=$ rating of perceived exertion, $\mathrm{VE}=$ ventilation, $\mathrm{VO}_{2}=$ oxygen uptake . 


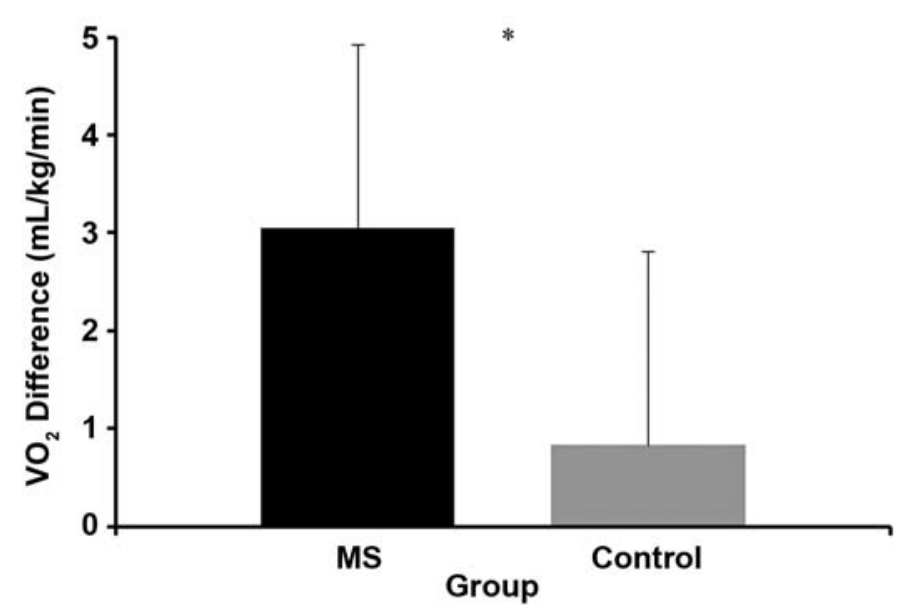

Figure 2.

Leg difference in oxygen uptake $\left(\mathrm{VO}_{2}\right)$ during single-leg cycling. Values are mean \pm standard deviation. ${ }^{*} p<0.05$ represents statistically significant differences in group means. MS = multiple sclerosis.

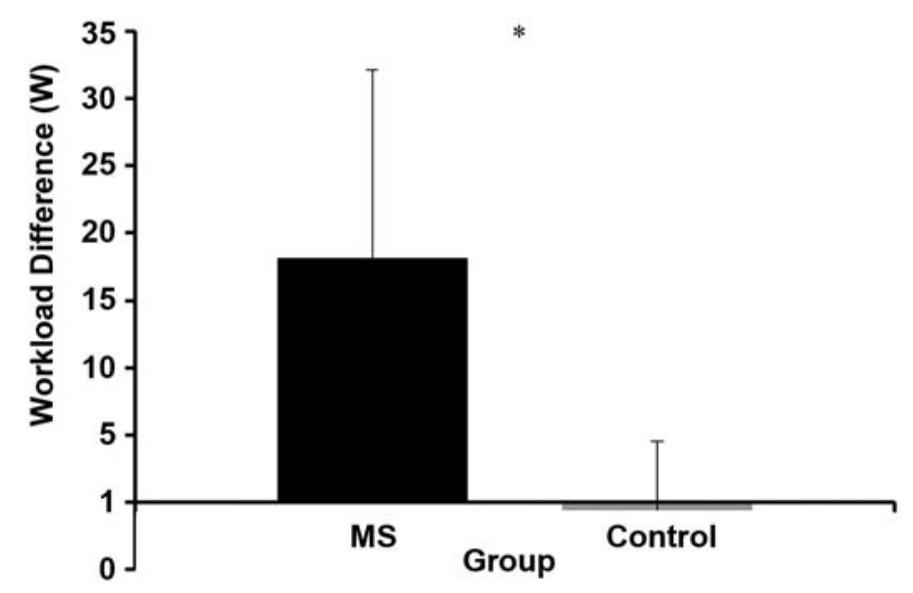

Figure 3.

Leg difference in peak workload during single-leg cycling. Values are means \pm standard deviation. ${ }^{*} p<0.05$ represents statistically significant differences in group means. MS = multiple sclerosis.

related to muscle physiology, function, and fatigue in people with MS appear to be interpreted based on data apparently collected from a single leg or single muscle group. For example, some reports are based on data from the left leg [24], while others are from the right leg [25] or the specified leg was unclear [10,26-27]. Some investigators have reported study findings based on tests using the weaker (more affected) side of the body $[8,28]$. To date, limited published information is available that describes interlimb differences in individuals with MS [14].
Activities of daily living such as walking require sufficient synchronization of bilateral motor unit recruitment and discharge rates. Typically, the legs are recruited bilaterally and limb preference may switch depending on the complexity and conditions during the movement [29]. Individuals with MS can be limited in their ability to activate motor units during bilateral movements, which may result in the development of compensatory strategies in recruitment patterns to their stronger (less affected) limb [30]. Therefore, the stronger (less affected) side might actually become stronger as a result of compensatory actions of the stronger leg in our group of individuals with MS. When looking at leg preference (dominant vs nondominant), four individuals in the MS group preferred a side (dominant) that was significantly weaker than their nondominant side. This was specific to our group with MS because the controls not only exhibited no significant bilateral differences but their stronger leg was their preferred (dominant) leg.

Bilateral differences in oxidative capacity and maximal aerobic capacity between legs are usually negligible [31-32]. For example, previous studies have shown no differences between legs in peak $\mathrm{VO}_{2}$ during single-leg cycling protocols at constant and incremental loads in both athletic and nonathletic groups [31-32]. These studies also report no differences in the magnitude of muscle activation (recruitment patterns) as measured by electromyography (EMG) [31-32]. Data from these studies suggest that each leg performs work and functions aerobically at approximately the same level [31]. In participants with MS, we found that the strong leg performed at relatively higher capacity than the weaker leg. Although we collected no EMG data in the present study, our observations may indicate dissimilar neural activation pattern in the weak leg in those with MS, indicated by the leg's premature task failure as evidence by the reduced performance during incremental cycling.

Our data might suggest that the weak leg limits aerobic exercise tolerance and performance. We did observe a correlation between the 6MWT and between-leg differences in peak workload ( $r=-0.77, p<0.05$ ), suggesting that $\sim 59$ percent of limitations in functional capacity might be explained by leg differences during dynamic actions. However, these data are preliminary at best and would need to be verified in a much larger study because of our small sample size. Additional research is needed to identify central and peripheral factors that might contribute to bilateral differences observed in our sample. Research is needed to identify whether bilateral differences 
can be reduced following training and physical therapy tailored to an individual who exhibits significant differences in strength and function between limbs (legs and arms). Despite the small sample size, our findings highlight the need for an emphasis on bilateral assessment and the need for therapies targeted at reducing such differences.

\section{CONCLUSIONS}

The major finding of this study was that the statistically significant bilateral differences in lower-limb strength and aerobic performance in a group of ambulatory individuals with MS were not observed in our sample of individuals without MS. The differences between legs in individuals with MS were greater when measured as work performance rather than maximal isometric strength. These data highlight the need for research studies and therapeutic interventions to account for differences in limb function. The observation of limb differences may be more apparent for functional activities rather than simpler measures of muscle strength. Finally, these leg differences should be considered when designing future research study protocols. Our findings highlight new information relevant to exercise therapy in people with MS; however, we appreciate that there are limitations to our study such as the small sample size and lack of ability to distinguish the influence of central and peripheral factors on bilateral differences. Additional research is needed to specifically assess muscle quality and function in individuals, such as those with MS, susceptible to developing bilateral differences.

\section{ACKNOWLEDGMENTS}

\author{
Author Contributions: \\ Study concept and design: R. D. Larson, L. J. White. \\ Acquisition of data (generating and gathering): R. D. Larson, \\ D. J. Larson, W. M. Pryor. \\ Analysis and interpretation of data: R. D. Larson, D. J. Larson, \\ K. K. McCully, L. J. White. \\ Drafting of manuscript: R. D. Larson. \\ Critical revision of manuscript for important intellectual content: \\ R. D. Larson, D. J. Larson, W. M. Pryor, K. K. McCully, L. J. White. \\ Statistical analysis: R. D. Larson, D. J. Larson. \\ Administrative, technical, or material support: L. J. White, \\ K. K. McCully. \\ Study supervision: L. J. White.
}

Financial Disclosures: The authors have declared that no competing interests exist.
Funding/Support: This material was unfunded at the time of manuscript preparation.

Additional Contributions: We would like to thank all of the participants for their involvement and cooperation during this study. Dr. Rebecca Larson and Dr. Daniel Larson are now with the Department of Health and Exercise Science, University of Oklahoma, Norman, Oklahoma.

Institutional Review: The University of Georgia Institutional Review Board approved this study.

Participant Follow-up: The authors plan to inform participants of the publication of this study.

\section{REFERENCES}

1. Romberg A, Virtanen A, Aunola S, Karppi SL, Karanko H, Ruutiainen J. Exercise capacity, disability and leisure physical activity of subjects with multiple sclerosis. Mult Scler. 2004;10(2):212-18. [PMID:15124769] http://dx.doi.org/10.1191/1352458504ms10010a

2. Freal JE, Kraft GH, Coryell JK. Symptomatic fatigue in multiple sclerosis. Arch Phys Med Rehabil. 1984;65(3): 135-38. [PMID:6703889]

3. Krupp LB, Alvarez LA, LaRocca NG, Scheinberg LC. Fatigue in multiple sclerosis. Arch Neurol. 1988;45(4): 435-37. [PMID:3355400] http://dx.doi.org/10.1001/archneur.1988.00520280085020

4. Fisk JD, Pontefract A, Ritvo PG, Archibald CJ, Murray TJ. The impact of fatigue on patients with multiple sclerosis. Can J Neurol Sci. 1994;21(1):9-14. [PMID:8180914]

5. Multiple Sclerosis Council for Clinical Practice Guidelines. Fatigue and multiple sclerosis: Evidence-based management strategies for fatigue in multiple sclerosis. Washington (DC): Paralyzed Veterans of America; 1998.

6. Rice CL, Vollmer TL, Bigland-Ritchie B. Neuromuscular responses of patients with multiple sclerosis. Muscle Nerve. 1992;15(10):1123-32. [PMID:1406770] http://dx.doi.org/10.1002/mus.880151011

7. Nielsen JF. Frequency-dependent conduction delay of motor-evoked potentials in multiple sclerosis. Muscle Nerve. 1997;20(10):1264-74. [PMID:9324083]

8. Garner DJ, Widrick JJ. Cross-bridge mechanisms of muscle weakness in multiple sclerosis. Muscle Nerve. 2003; 27(4):456-64. [PMID:12661047] http://dx.doi.org/10.1002/mus.10346

9. Kent-Braun JA, Sharma KR, Miller RG, Weiner MW. Postexercise phosphocreatine resynthesis is slowed in multiple sclerosis. Muscle Nerve. 1994;17(8):835-41. [PMID:8041390] http://dx.doi.org/10.1002/mus.880170802

10. Kent-Braun JA, Ng AV, Castro M, Weiner MW, Gelinas D, Dudley GA, Miller RG. Strength, skeletal muscle composition, 
and enzyme activity in multiple sclerosis. J Appl Physiol. 1997;83(6):1998-2004. [PMID:9390973]

11. Kent-Braun JA, Walker CH, Weiner MW, Miller RG. Functional significance of upper and lower motor neuron impairment in amyotrophic lateral sclerosis. Muscle Nerve. 1998;21(6):762-68. [PMID:9585330]

12. DeMyer WE. Technique of the neurological examination. 5th ed. New York (NY): McGraw Hill; 2004.

13. Chung LH, Remelius JG, Van Emmerik RE, Kent-Braun JA. Leg power asymmetry and postural control in women with multiple sclerosis. Med Sci Sports Exerc. 2008; 40(10):1717-24. [PMID:18799980]

http://dx.doi.org/10.1249/MSS.0b013e31817e32a3

14. White LJ, Dressendorfer RH. Factors limiting maximal oxygen uptake in exertional monoparesis. Mult Scler. 2005;11(2):240-41. [PMID:15794400] http://dx.doi.org/10.1191/1352458505ms1151oa

15. Thoumie P, Lamotte D, Cantalloube S, Faucher M, Amarenco G. Motor determinants of gait in 100 ambulatory patients with multiple sclerosis. Mult Scler. 2005;11(4): 485-91. [PMID:16042234]

http://dx.doi.org/10.1191/1352458505ms1176oa

16. Lambert CP, Archer RL, Evans WJ. Muscle strength and fatigue during isokinetic exercise in individuals with multiple sclerosis. Med Sci Sports Exerc. 2001;33(10):1613-19. [PMID:11581542]

http://dx.doi.org/10.1097/00005768-200110000-00001

17. Larson RL, White LJ. Asymmetrical hip bone density in multiple sclerosis. Int J MS Care. 2011;13(1):43-47. http://dx.doi.org/10.7224/1537-2073-13.1.43

18. Kurtzke JF. Rating neurologic impairment in multiple sclerosis: an expanded disability status scale (EDSS). Neurology. 1983;33(11):1444-52. [PMID:6685237] http://dx.doi.org/10.1212/WNL.33.11.1444

19. Whaley MH, Brubaker PH, Otto RM, Armstrong LE, et al. ACSM's guidelines for exercise testing and prescription. 7th ed. Philadelphia (PA): Lippincott Williams \& Wilkins; 2006.

20. Borg GA. Perceived exertion. Exerc Sport Sci Rev. 1974; 2:131-53. [PMID:4466663] http://dx.doi.org/10.1249/00003677-197400020-00006

21. Guyatt GH, Sullivan MJ, Thompson PJ, Fallen EL, Pugsley SO, Taylor DW, Berman LB. The 6-minute walk: a new measure of exercise capacity in patients with chronic heart failure. Can Med Assoc J. 1985;132(8):919-23. [PMID:3978515]

22. McGavin CR, Gupta SP, McHardy GJ. Twelve-minute walking test for assessing disability in chronic bronchitis. BMJ. 1976;1(6013):822-23. [PMID:1260350]

http://dx.doi.org/10.1136/bmj.1.6013.822

23. Cohen J. Statistical power analysis for the behavioral sciences. Hillsdale (NJ): L. Erlbaum Associates; 1988.

24. de Haan A, de Ruiter CJ, van Der Woude LH, Jongen PJ. Contractile properties and fatigue of quadriceps muscles in multiple sclerosis. Muscle Nerve. 2000;23(10):1534-41. [PMID:11003788]

25. Ng AV, Miller RG, Gelinas D, Kent-Braun JA. Functional relationships of central and peripheral muscle alterations in multiple sclerosis. Muscle Nerve. 2004;29(6):843-52.

[PMID:15170617]

http://dx.doi.org/10.1002/mus.20038

26. Ng AV, Dao HT, Miller RG, Gelinas DF, Kent-Braun JA. Blunted pressor and intramuscular metabolic responses to voluntary isometric exercise in multiple sclerosis. J Appl Physiol. 2000;88(3):871-80. [PMID:10710381]

27. Sharma KR, Kent-Braun J, Mynhier MA, Weiner MW, Miller RG. Evidence of an abnormal intramuscular component of fatigue in multiple sclerosis. Muscle Nerve. 1995; 18(12):1403-11. [PMID:7477063] http://dx.doi.org/10.1002/mus.880181210

28. Ng AV, Miller RG, Kent-Braun JA. Central motor drive is increased during voluntary muscle contractions in multiple sclerosis. Muscle Nerve. 1997;20(10):1213-18. [PMID:9324075]

29. Hart S, Gabbard C. Brief communication: bilateral footedness and task complexity. Int J Neurosci. 1996;88(1-2): 141-46. [PMID:9003971] http://dx.doi.org/10.3109/00207459608999819

30. Teixeira MC, Teixeira LA. Leg preference and interlateral performance asymmetry in soccer player children. Dev Psychobiol. 2008;50(8):799-806. [PMID:18688809] http://dx.doi.org/10.1002/dev.20322

31. Carpes FP, Diefenthaeler F, Bini RR, Stefanyshyn D, Faria IE, Mota CB. Does leg preference affect muscle activation and efficiency? J Electromyogr Kinesiol. 2010;20(6): 1230-36. [PMID:20729097] http://dx.doi.org/10.1016/j.jelekin.2010.07.013

32. Sargeant AJ, Davies CT. Forces applied to cranks of a bicycle ergometer during one- and two-leg cycling. J Appl Physiol. 1977;42(4):514-18. [PMID:863811]

Submitted for publication October 7, 2011. Accepted in revised form June 21, 2012.

This article and any supplementary material should be cited as follows:

Larson RD, McCully KK, Larson DJ, Pryor WM, White LJ. Bilateral differences in lower-limb performance in individuals with multiple sclerosis. J Rehabil Res Dev. 2013;50(2):215-22.

http://dx.doi.org/10.1682/JRRD.2011.10.0189

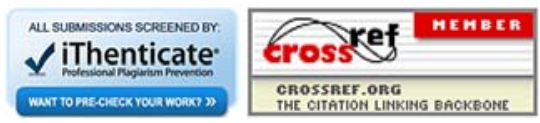


